Natural Hazards and Earth System Sciences (2004) 4: 323-337

SRef-ID: 1684-9981/nhess/2004-4-323

(C) European Geosciences Union 2004

\title{
Analysis of an intense bora event in the Adriatic area
}

\author{
D. Cesini ${ }^{1}$, S. Morelli ${ }^{1}$, and F. Parmiggiani ${ }^{2}$ \\ ${ }^{1}$ Department of Physics-University of Modena and Reggio Emilia, Italy \\ ${ }^{2}$ Institute of Atmospheric Sciences and Climate CNR, Bologna, Italy
}

Received: 2 June 2003 - Revised: 16 February 2004 - Accepted: 24 February 2004 - Published: 19 April 2004

\begin{abstract}
Numerical simulations of a bora event, recently occurred in the Adriatic area, are presented. Two reference runs at different horizontal resolution (about $20 \mathrm{~km}$ and $8 \mathrm{~km}$ ) describe the case. Initial conditions for the atmospheric model integration are obtained from ECMWF analyses. Satellite data are used for comparisons. A further run at horizontal resolution of $8 \mathrm{~km}$, using initial satellite sea surface temperatures, is performed to evaluate their impact on the low level wind over the Adriatic Sea. All the simulations are carried out with 50 layers in the vertical. Numerous aspects of the simulations are found to be in agreement with the understanding as well as the observational knowledge of bora distinctive characteristics. Satellite data and model results indicate that a more realistic simulation of the bora wind over the sea is achieved using the model with $8 \mathrm{~km}$ horizontal resolution and that the low level wind in this case is sensitive, though weakly, to the difference between the used sea surface temperature fields. Simulation results also show that both wind intensity and the area around wind peaks tend to increase when relatively higher sea surface temperatures are used.
\end{abstract}

\section{Introduction}

Bora is a cold, low-level wind blowing mainly from the north-east, across the mountain barrier of the Dinaric Alps, parallel to the eastern Adriatic coast. It is often more intense and frequent in winter and in the night. Bora is strong and can have damaging effects, affecting coastal areas and significantly modifying the Adriatic Sea status. Needless to say, it makes difficult any kind of civil transportation.

In this paper a real case of Adriatic bora, occurred between 24 and 27 June 2002, is simulated by means of an atmospheric numerical model and of satellite data. The simulated low level wind over the Adriatic Sea is compared with satel-

Correspondence to: S. Morelli

(morelli@unimo.it) lite wind data. The bora wind features are regulated by multiscale factors: being greatly influenced by orography, high resolution is needed to obtain a good terrain representation but, the synoptic situation of the atmosphere that surrounds the Adriatic Sea must be known as well.

Strong air-sea interaction occurs during bora events. The wind has effect on the sea circulation, as shown by recent numerical modelling studies on the response of the Adriatic Sea to the bora wind (Orlić et al., 1994; Rachev and Purini, 2001). After a winter bora episode, an Advanced Very High Resolution Radiometer (AVHRR) satellite image, presented by Beg Paklar et al. (2001), revealed a cold filament protruding from the Italian coastal area toward the open sea, attributed to an "unusual" behaviour of the Po River water.

In our study, MultiChannel Sea Surface Temperature (MCSST) (McClain et al., 1985; Robinson et al., 1984) satellite images from AVHRR were used. As clearly stated in the paper by McClain et al. (1985) the term MCSST refers to sea skin temperature at a depth of a fraction of a millimetre. In the studied event, the MCSST images show that in the course of few hours a significant change of the sea skin temperature occurred in the northern Adriatic.

Reversing the point of view, the impact of wind-generated waves on the structure and evolution of a bora case were investigated by Doyle (2002), using a coupled atmosphereocean wave modelling system. In his study, the wave coupling appeared to have only a small effect on the atmospheric wind. Enger and Grisogono (1998) in a series of numerical experiments using a 2-D model found a high correlation between the Sea Surface Temperature (SST) and the bora offshore propagation length. Changing the surface temperature meant altering the coastal atmospheric boundary layer buoyancy frequency and, as a consequence, the dynamical development of the wind.

The bora event investigated in this paper, even if not among the strongest episodes, is interesting as it happened after a period of intense insolation which strongly warmed the sea surface. 


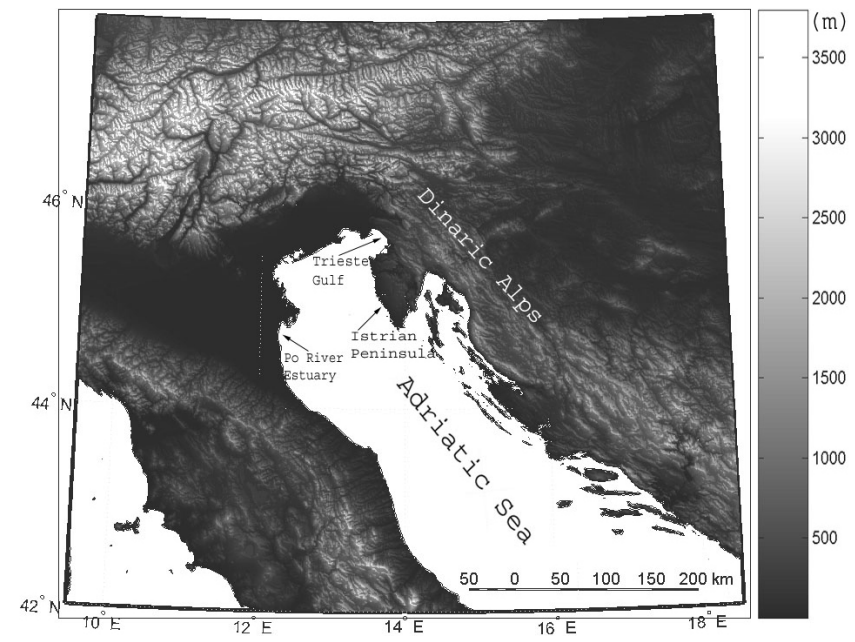

Fig. 1. Orography of the Adriatic region. Names of the main places and mountains quoted in the text are included.

The case is described by different numerical simulations; one of these makes use of MCSSTs as initial values in order to evaluate the impact of changing the initial surface temperature on the development of the wind over the sea.

A brief introduction to bora wind and to its classification on the basis of the meteorological situations is the subject of Sect. 2. A description of the used numerical model and a description of the used satellite data and simulations characteristics are given in Sects. 3 and 4, respectively. A presentation of the event mesoscale pattern and a sensitivity study of the SST initial value influence on bora low level wind are presented in Sects. 5 and 6, respectively. Conclusions are discussed in the last Sect. 7.

\section{The bora wind}

Bora is a strong downslope wind along the eastern Adriatic coast. Cold air can reach hourly averaged speed of $35 \mathrm{~m} / \mathrm{s}$ with gusts exceeding $55 \mathrm{~m} / \mathrm{s}$. Other local winds (like Boulder (USA) winds, Antarctic slope winds, Hokkaido (Japan) and Novorossijsk (Russia) winds) have been referred to as boratype winds.

Bora was thought as the prototype of a fall wind, but works by Smith $(1985,1987)$, Smith and Sun (1987) related the bora flow to the hydraulic theory as first proposed by Long $(1953,1954,1955)$. Alternative theories which relate the origin of downslope winds to large amplitude vertical propagating mountain waves, were proposed by Eliassen and Palm (1961), Klemp and Lilly (1975), Clark and Peltier (1977, 1984).

According to the shallow water hydraulic theory, downslope winds originate when a subcritical flow (Froude number $<1)$ reaches a mountain, and a transition to supercritical flow occurs around the top of the obstacle, so that on the lee side the flow is supercritical (Froude number $>1$ ). This condition involves the wind accelerating during the whole path over the mountain. Subcritical conditions are eventually restored by an hydraulic jump. Smith (1985) and Smith and Sun (1987) found special solutions of Long's equations and were the first to suggest that bora wind might have hydraulic character.

The two dimensional hydraulic theory is able to explain a considerable part of the events, however, its basic assumptions can be too restrictive for the real atmosphere. This can create discrepancies when analytical results are compared with observation or simulation of real 3-D events. IvančanPicek and Tutiš (1996), in example, found that the theory is not completely exhaustive of some bora situations which develop in the southern Adriatic and that a 3-D multiscale approach is needed because bora onset, longevity and severity are closely related to mesoscale features as well as to local patterns.

The bora storms appear as a consequence of a cold air outbreak upstream the Dinaric Alps and of a pressure gradient across the mountain range. The wind development is greatly influenced by topography pattern in Adriatic area, so mountains shape and channels are important component of the windstorms. The complexity of the orography of the region is shown in Fig. 1. An example of bora sensitivity to the mountain height and shape is given by Lazić and Tošić (1998). They performed a series of 3-D numerical experiments to simulate the development of the wind when the mountains height was changed from zero to $200 \%$ of the value of the control mountains elevation. They found that bora wind occurred only in the case in which the real mountain height was used: too low barriers led to a decrease of air accumulation in front of the mountains, while too high barriers were responsible of a complete blocking effect. In some places along the Adriatic coast, the mountain configuration allows strong channelling effects which increase the strength of the events. An example is the Vratnik Pass, south of Istrian Peninsula near Senj. In this region, the mountain range upstream of the wind belongs to a fairly low lying and narrow area of the Dinaric Alps and violent bora occurs.

Bora can be classified in relation to the meteorological situation present over Europe (Yoshino, 1976). In each case, the pressure is higher inland to the Dinaric Alps and lower over the Adriatic Sea. According to a climatological study by Camuffo (1990) the following types can be distinguished:

- Anticyclonic bora - associated with a strong high pressure over western Europe or eastern Atlantic; isobaric contour lines aloft tend to be perpendicular to the Alps. The low pressure over northern Adriatic can be deepened by cyclogenesis. This kind of bora is characterized by overcast sky and often by precipitation.

- White bora - associated with high pressure over central or eastern Europe. Isobaric contour lines tend to be parallel to the Alps. It is characterised by clear sky and usually occurs in winter.

- Cyclonic bora - associated with a depression that lies west of the Alps. Rainfall may be present, but not so severe as in the case of the dark bora. 
- Dark bora - associated with a depression over the central Mediterranean that draws cold air from northern Europe and spins warm, moist air toward northern Adriatic producing clouds and intense precipitation.

In all the cases listed above the same condition is satisfied: a supply of low-level cold air from north or north-east is present in the region of Dinaric Alps. Usually this air is confined by an upper inversion layer and/or by a flow with different velocity direction (this leads to the presence of a critical layer). However Klemp and Durran (1987) showed that neither the inversion nor the critical layer are essential in the dynamical development of the bora flow.

\section{The Eta model}

The used mesoscale model is a recent version of the Eta Model, a three-dimensional, primitive equations, grid-point model. A version of this model is currently operational at the National Centers for Environmental Prediction (NCEP) of the U.S. National Weather Services.

Specific characteristic of the model is the use of the quasihorizontal $\eta$ vertical coordinate, introduced by Mesinger (1984) to minimize the problems associated with steeply sloping coordinate surfaces (Mesinger et al., 1988; Mesinger and Black, 1992). However the model can perform run with terrain following coordinates as well.

The vertical coordinate $\eta$ is defined by:

$\eta=\left(\frac{p-p_{T}}{p_{\text {sfc }}-p_{T}}\right)\left(\frac{p_{\text {ref }}\left(Z_{\text {sfc }}\right)-p_{T}}{p_{\text {ref }}(0)-p_{T}}\right)$

where $p, p_{T}, p_{\text {sfc }}$ are respectively grid-point, model top and surface pressures; $p_{\text {ref }}$ is a suitable defined reference pressure depending on altitude $(Z)$ (i.e. from a polytropic atmosphere), $Z_{\text {sfc }}$ is the ground surface height. On the horizontal, the semi-staggered Arakawa E grid (Arakawa and Lamb, 1977) and a rotated spherical coordinate system are used. The grid is obtained by moving the point where the equator crosses the prime meridian to the integration domain centre. The numerically advantageous effect is to minimize the convergence of meridians.

The model topography is represented as discrete steps whose tops coincide exactly with the model's layer interfaces. The velocity components at the sides of mountains are set to zero. The prognostic variables are defined in the middle of the layers. A more detailed description of the dynamical part of the model can be found in Mesinger et al. (1988). Time-dependent lateral boundary values on model's outermost row of points are obtained by interpolation from analysed fields. The integration domain begins with the third outermost row. The values of the second outermost row are a blend of those along the boundary and those in the third row.

The physical package of the model includes: the Geophysical and Fluid Dynamics Laboratory (GFDL) radiation schemes, the Betts-Miller-Janjić convective parameterisation (Janjić, 1994), a cloud prediction scheme (Zhao et al., 1997), an orographic form drag scheme (Georgelin et al., 1994), a soil model with four layers (Chen et al., 1996) and the revised Mellor-Yamada level 2.5 turbulence scheme for the planetary boundary layer (Janjić, 1996). Turbulent processes in the surface layer are represented by means of Monin Obukhov similarity theory with the Paulson scheme (Paulson, 1970) on land points and with a scheme derived from Mellor-Yamada level 2 formulation (Lobocki, 1993) on sea points. Viscous sublayer parameterisation is also present on sea points. Sea surface temperatures, interpolated to the Eta Model grid, remain constant to the initial values throughout the simulations.

The model is able to perform hydrostatic and nonhydrostatic run.

\section{Methods}

\subsection{MCSST images}

MCSST images are obtained by processing data from AVHRR, the sensor mounted on NOAA satellites, which works on 5 channels with a spatial resolution of $1.1 \mathrm{~km}$ at nadir. Raw AVHRR data over the area of interest were acquired by the NOAA receiving station of the Institute of Atmospheric Sciences and Climate (ISAC) CNR located in Bologna. The days of the bora event were only few days before the launch of NOAA-17, thus only two satellites, NOAA-12 and NOAA-16, were operating at the time, with about 8 satellite passes per day captured by the Bologna station. AVHRR data processing consists of the following steps:

1. Calibration.

The solar channels 1 and 2 are calibrated into percent albedo as described by NOAA manual. The thermal infrared data (channels 3, 4 and 5) are converted from raw counts to radiances with a linear relationship based on the raw count value associated with cold space and the raw count value associated with the temperature of an onboard blackbody.

A slight non-linearity in channels 4 and 5 is corrected using a quadric function of radiance. Lastly,the infrared radiances are converted to brightness temperatures (degrees Celsius) using the inverse Plank function. They are derived via a temperature-radiance look-up table.

2. Cloud screening and clearing.

To ensure that MCSST is derived only for cloud free water surfaces, two cloud tests are performed. They are based on the principal characteristics of water bodies, considering typical spectral and textural parameters such as dark, warm, and homogenous surface. All pixels which are flagged as CLOUD or NO SST are excluded from all further processes.

\section{MCSST.}

The applied formula is based on the brightness temperatures of AVHRR channels 4 and 5 (T4, T5) (McClain et 


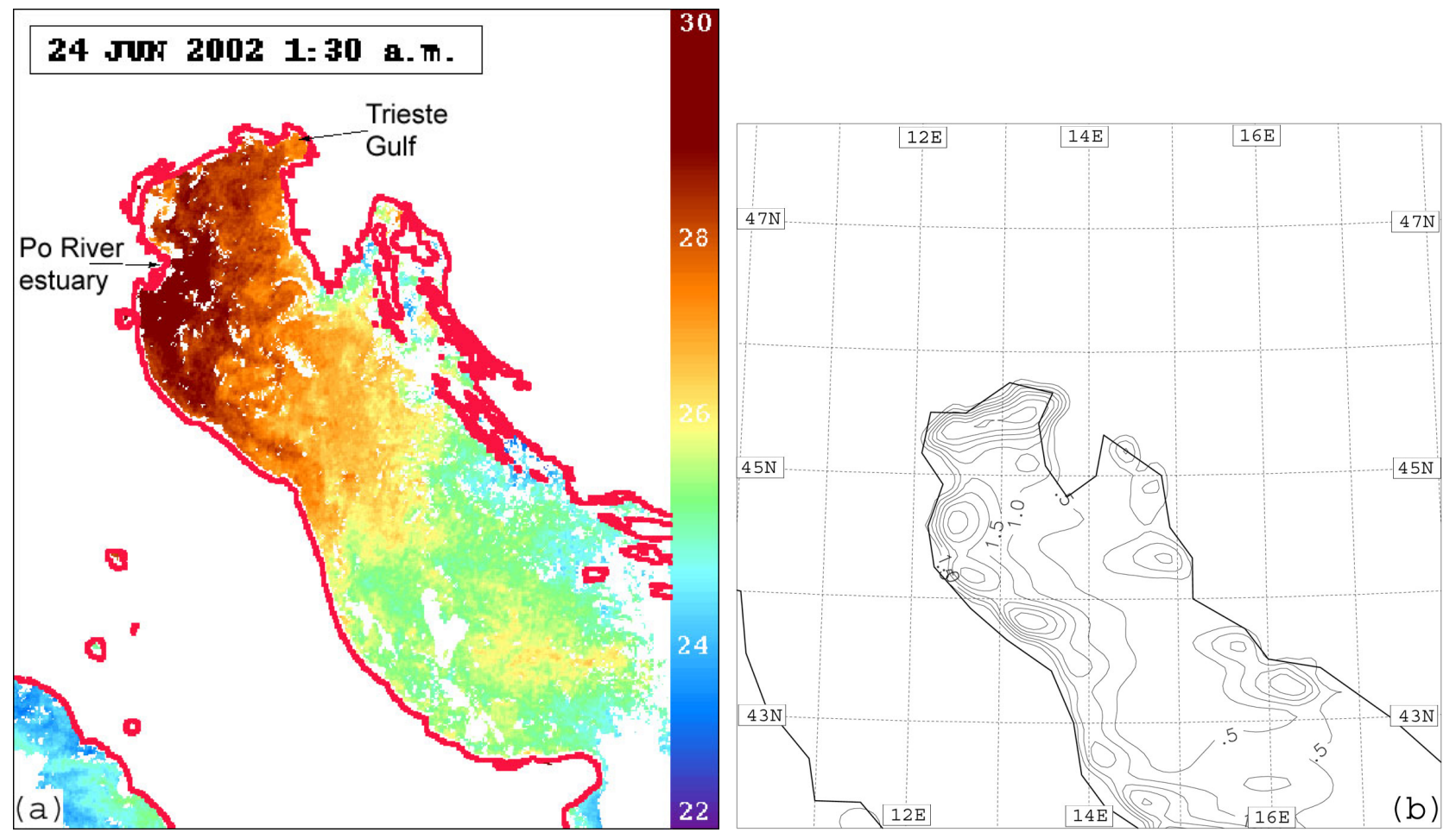

Fig. 2. (a) MCSSTs $\left({ }^{\circ} \mathrm{C}\right)$ at 01:30 UTC 24 June 2002; (b) differences between MCSSTs and ECSSTs interpolated to the fine grid. Contour line step is $0.5 \mathrm{~K}$.

al., 1985). This technique is known as the "Split Window Technique" and corrects atmospheric attenuation mainly caused by water vapour absorption in the atmosphere; if not accounted for, this absorption can lead to a significant drop in derived brightness temperatures, thus to a significant error in surface temperature computation.

\section{Composite images.}

In order to reduce cloud cover, daily composite images are produced using up to eight different NOAA acquisitions: these images are composed together by taking the maximum temperature value at every pixel's position.

Steps 1 to 4 are performed by means of specific commands of the commercial software package TeraScan (TeraScan User Manual, 2002) in use at ISAC.

\subsection{QuikSCAT wind data.}

Satellite sea wind data obtained by QuikSCAT instrument are downloaded from NASA/PODAAC (Physical Oceanographic Distributed Active Archive) at JPL (Jet Propulsion Laboratory). QuikSCAT Level3 data have a spatial resolution of $0.25^{\circ}$ and are tabulated two times per day, for the morning (ascending) and for the afternoon (descending) satellite pass.

\subsection{The characteristics of the numerical simulations}

Simulations start at 00:00 UTC 24 June 2002 and last $72 \mathrm{~h}$. Runs are performed at two different horizontal resolutions:

(a) The coarse-grid run integrates over a horizontal domain defined between $6.3^{\circ} \mathrm{E}$ and $21.7^{\circ} \mathrm{E}$ and between $37.8^{\circ} \mathrm{N}$ and $49.8^{\circ} \mathrm{N}\left(5^{\circ} \times 6^{\circ}\right.$ on the rotated terrestrial sphere), centred at $\left(14^{\circ} \mathrm{E}, 44^{\circ} \mathrm{N}\right)$, with a resolution of about $20 \mathrm{~km}$ (approximate distance between two mass points on the semi-staggered Arakawa E grid). The grid has $81 \times 97$ points.

(b) The fine-grid runs use a smaller domain, defined between $9.5^{\circ} \mathrm{E}$ and $18.5^{\circ} \mathrm{E}$ and between $41.9^{\circ} \mathrm{N}$ and $47.9^{\circ} \mathrm{N}\left(3^{\circ} \times 3^{\circ}\right.$ on the rotated terrestrial sphere $)$, but a higher resolution of about $8 \mathrm{~km}$ (approximate distance between two mass points on the semi-staggered Arakawa E grid). Domain centre is at $\left(14^{\circ} \mathrm{E}, 45^{\circ} \mathrm{N}\right)$, the grid has $121 \times 121$ points.

All runs use $\eta$ as vertical coordinate and the hydrostatic assumption. European Centre for Medium-range Weather Forecast $(\mathrm{ECMWF})$ analyses, at $0.36^{\circ} \times 0.36^{\circ}$ horizontal resolution, provide initial and boundary conditions (updated every $6 \mathrm{~h}$ ). The model initial SSTs are obtained by bilinear interpolation from ECMWF surface temperatures or by satellite data, while the initial land surface temperatures are recomputed by the hydrostatic equation and using the step orography of the model. 

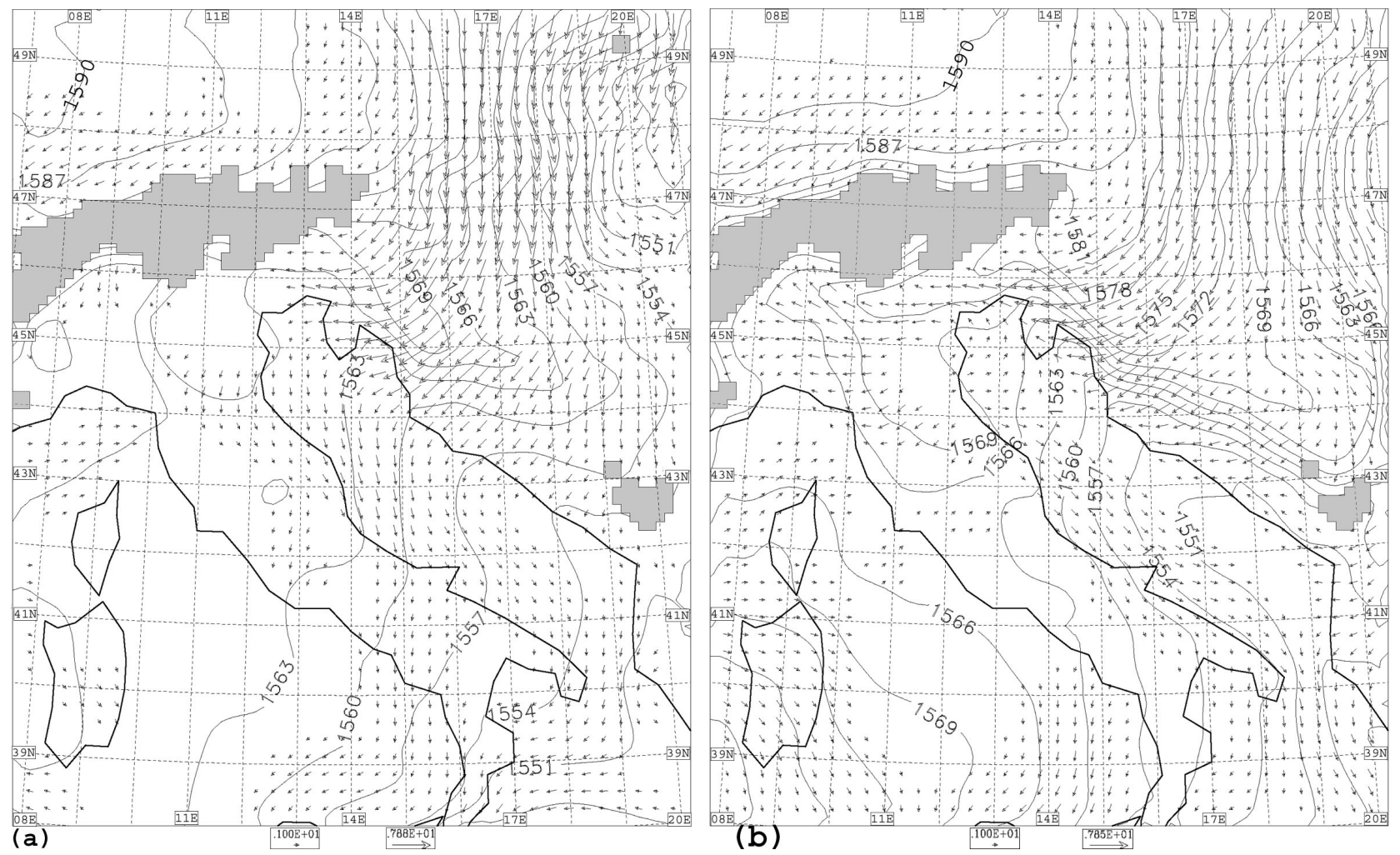

Fig. 3. $850 \mathrm{hPa}$ geopotential height (m) and wind vectors obtained with the coarse grid run (run A): (a) at 00:00 UTC 25 June 2002; (b) at 10:00 UTC 25 June 2002.

Shaded areas are under orography. Contour line step is $3 \mathrm{~m}$. Vectors are drawn in a reduced number of points to obtain greater readability. No arrows are displayed if wind speed $<1 \mathrm{~m} / \mathrm{s}$.

A vertical domain resolved with $50 \eta$-layers from sea level to $25 \mathrm{hPa}(\approx 22.4 \mathrm{~km})$ is used in the presented runs.

The depths of the layers slowly increase as higher levels are approached, so that the vertical resolution is higher near the bottom of the domain. The depths range from $20 \mathrm{~m}$ to $3300 \mathrm{~m}$ at the domain top, with 41 model levels in the first $10 \mathrm{~km}$. With the lowest model layer depth chosen to be $20 \mathrm{~m}$, the height of the lowest model level above the sea surface is $10 \mathrm{~m}$. As already mentioned, the prognostic variables are considered valid at layers mid-points.

Integration time step is $36 \mathrm{~s}$ for the coarse grid and $18 \mathrm{~s}$ for the fine grid runs. Model output is stored to media every hour for all runs.

Orography is built from the DEM (Digital Elevation Model) GTOPO30 data set, which provides elevation data at a resolution of 30 " $\times 30$ ". Whenever horizontal resolution is changed, orographic heights are recomputed accordingly from the DEM data set.

A total of three runs will be considered : two (one at the coarse grid resolution and one at the fine grid resolution) reference runs and a SST sensitivity run.

The reference runs are initialised with interpolated ECMWF sea skin temperature (indicated by ECSST) data, while in the sensitivity run MCSSTs are used. MCSSTs, shown in Fig. 2a, are taken from the satellite pass closest to the model integration starting time. White spots are clouds and an interpolation procedure to fill these gaps is necessary before passing the data to the model. The difference between interpolated ECSST and MCSST is shown in Fig. 2b for the finer grid. The area shown is the integration domain of the higher resolution runs. Differences are evident in particular in the areas of the Po river outflow and of the Trieste Gulf (indicated by arrows in Fig. 2a). At the time of initialisation (00:00 UTC 24 June 2002) land was colder than water especially in the northern Adriatic, so the interpolation of ECSSTs to the fine grid resolution, combined with the low resolution of original data, could have lowered the temperature of the near coast sea-points, increasing the differences with the surface temperature obtained from the high resolution data. The presence of mountains just behind the coast could have accentuated this effect.

It must be stressed however that, in every run, SSTs are held constant at the value of the integration starting time during the whole simulation. To summarise, three hydrostatic Eta runs are presented in this paper:
A) A coarse grid run with ECSST initialisation.
B) A fine grid run with ECSST initialisation.
C) A fine grid run with MCSST initialisation.

A) and B) are considered reference runs while C) is used as SST sensitivity run. 

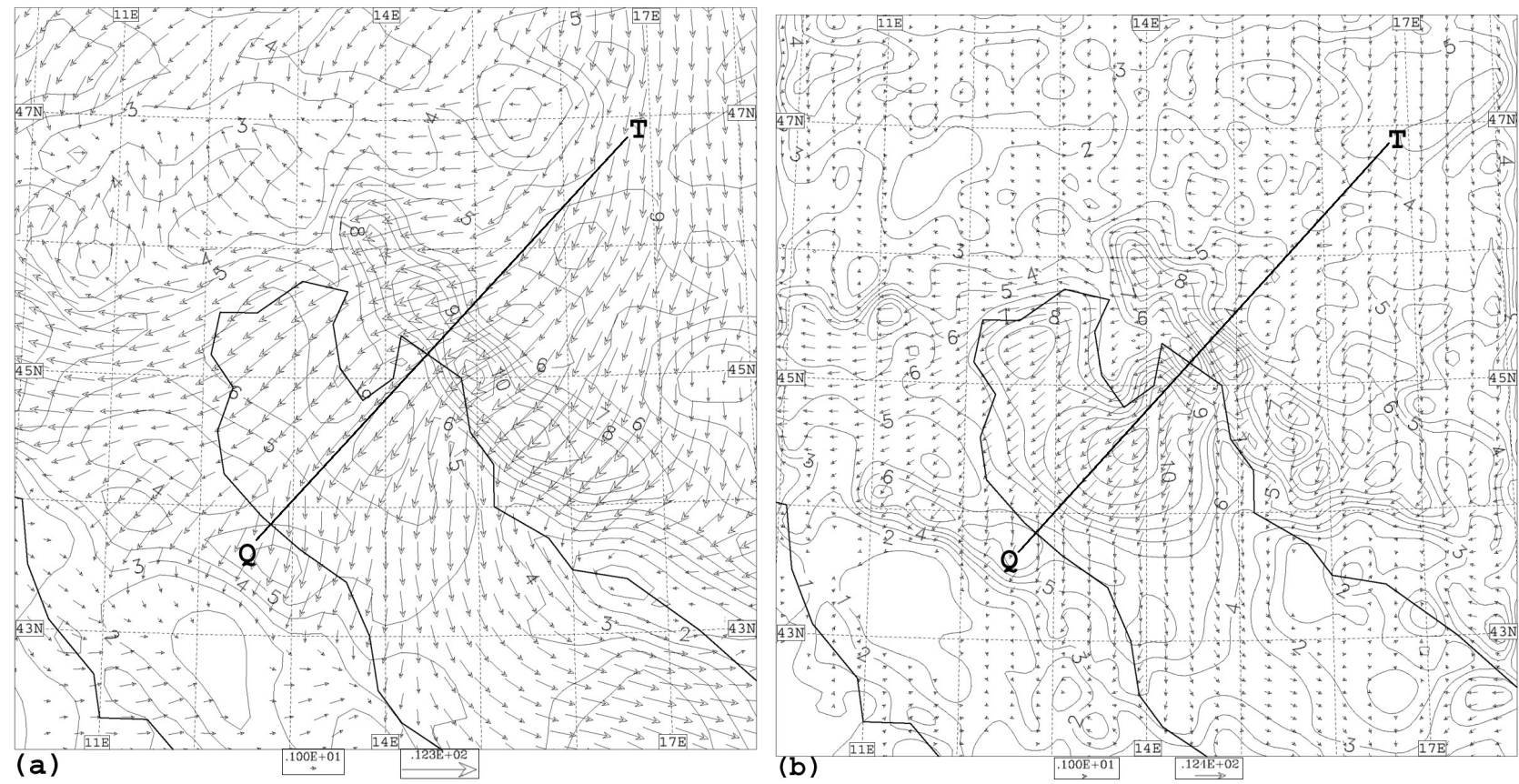

Fig. 4. Speed (m/s) and direction of the $10 \mathrm{~m}$ wind at 10:00 UTC 25 June 2002: (a) calculated by the coarse grid run (run A), the area shown is a portion of the integration domain; (b) calculated by the fine grid run (run B).

Contour line step is $1 \mathrm{~m} / \mathrm{s}$. Vectors are drawn in a reduced number of points to obtain greater readability. No arrows are displayed if wind speed $<1 \mathrm{~m} / \mathrm{s}$. The position of the cross-sections of Figs. 5 and 6 is also shown.

\section{The mesoscale pattern of the simulated event}

This section describes the event mesoscale pattern as it results from the simulations; in particular, the characteristics of the low level wind are presented. At the end of the section, a comparison with observational data will be shown.

First, runs A and B (according to the definition given in the paragraph 4.3) are considered. Since the 24 June 2002 the geopotential height of the $850 \mathrm{hPa}$ isobaric surface shows an anticyclonic area located north of the Alps, slowly moving eastward. Figure 3a represents the geopotential field and wind vectors at this isobaric surface after $24 \mathrm{~h}$ of simulation (00:00 UTC 25 June 2002) in the larger integration domain. At this time an air flow from northern Europe is deflected around the east Alps, resulting in a cold air inflow into northern Adriatic area. In the meanwhile a geopotential gradient almost perpendicular to the Dinaric Alps is building up (Fig. 3b). The cold air outbreak at the lowest levels is the bora wind onset. A strong horizontal pressure gradient through the barrier of the mountains and an intense northeasterly flow are two distinctive features of the bora events (Morelli and Berni, 2003 and Lazić and Tosic,1998). During the third day of the simulations (26 June 2002) high pressure places itself north - east of the Alps and a cold air flow, even if less intense, is still reaching the Dinaric Alps. On the whole, the event begins approximately at 00:00 UTC 25 June and ends about at 12:00 UTC 26 June.

On 25 June, clouds are present over the northern Adriatic while clear sky characterises the last part of the event. Fol- lowing the previous classification of bora types (Sect. 1), in the beginning the event has characteristics of an anticyclonic bora, and subsequently resembles a white bora. Low level wind $(10 \mathrm{~m})$ speed and direction at 10:00 UTC 25 June for the coarser grid are represented in Fig. 4a, while the same fields at the same time for the finer grid run are in Fig. 4b: both fields show the advection of air towards Dinaric Alps from northern Europe and the acceleration that this air experiences as it reaches the mountains. Acceleration tends to begin in the upwind side of the mountains as pointed out by aerial observations in previous events (Smith, 1987) and prescribed by the hydraulic theory. Both resolution runs suggest this effect. However wind is more intense and it does not develop uniformly in the whole area of the northern Adriatic if high resolution is adopted. The increase of the wind speed occurs offshore regions known from observations as favourite areas of strong bora (Jurčec, 1980/1981). This is due to the improved representation of the orography, in particular of the Dinaric Alps and shows the orographic character of the wind. The effects of the bora alongshore variability and the importance of an accurate realistic wind field to simulation of the offshore spreading of the Po River water were pointed out by Beg Paklar et al. (2001).

Two wind streams, one in the Trieste Gulf and the other (wider and stronger) south of the Istrian Peninsula, are clearly visible in the finer grid. The first one reaches its speed maximum (about $8 \mathrm{~m} / \mathrm{s}$ ) about at 05:00 UTC 25 June, while the second at 10:00 UTC on the same day. 

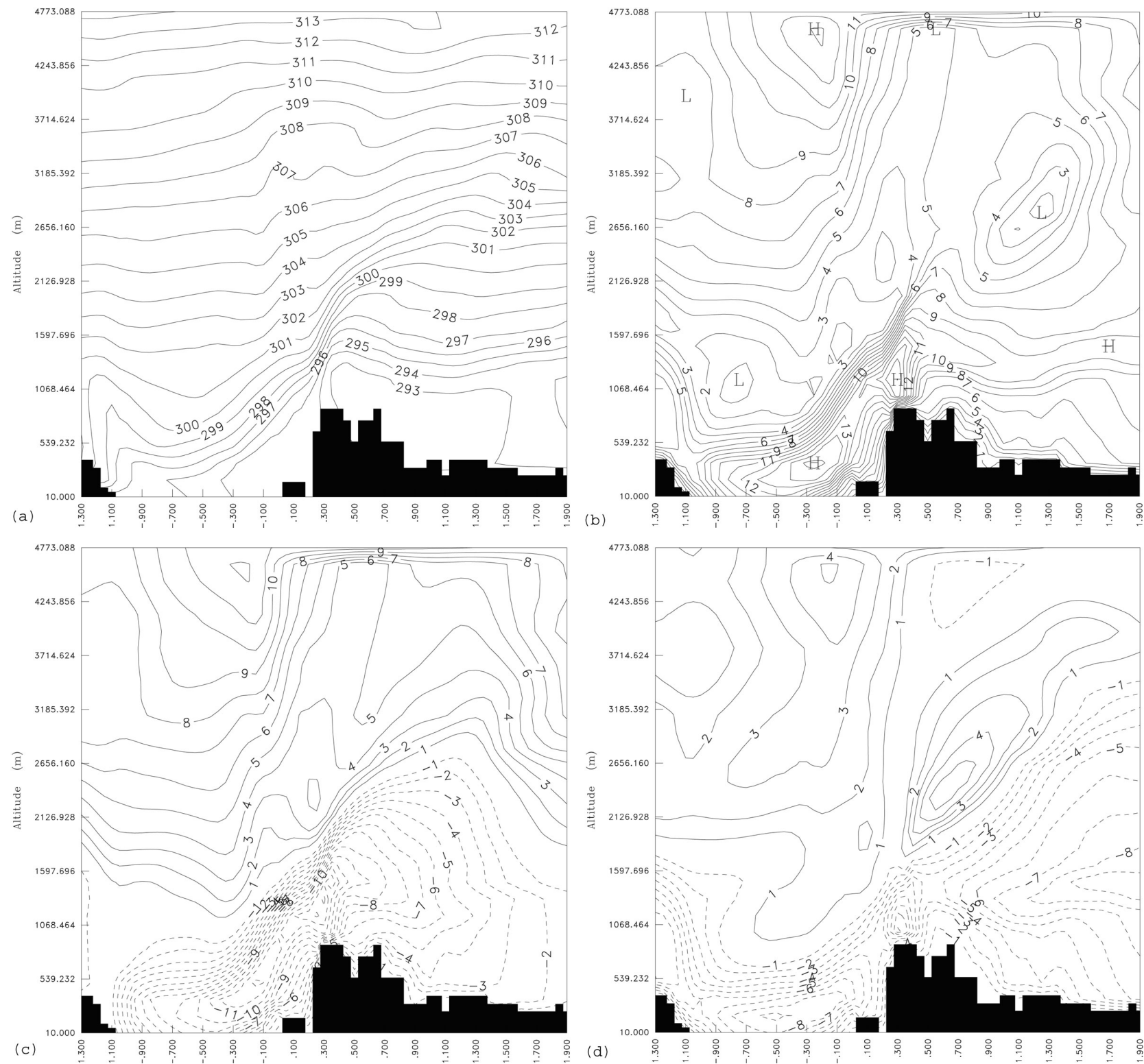

Fig. 5. Cross-sections calculated by the high resolution run (run B) at 10:00 UTC 25 June 2002: (a) potential temperature (K), contour line step is $1 \mathrm{~K}$; (b) total wind speed $(\mathrm{m} / \mathrm{s})$, contour line step is $1 \mathrm{~m} / \mathrm{s} ;(\mathbf{c})$ zonal wind component $(\mathrm{m} / \mathrm{s})$, contour line step is $1 \mathrm{~m} / \mathrm{s}$; (d) meridional wind component $(\mathrm{m} / \mathrm{s})$, contour line step is $1 \mathrm{~m} / \mathrm{s}$. Dashed lines mean negative values. On the horizontal axis arbitrary units are reported: each division corresponds to about $30 \mathrm{~km}$.

Wind reaches a speed of about $12 \mathrm{~m} / \mathrm{s}$ in the second stream of the fine grid run while the maximum speed of the coarse grid run is of $7 \mathrm{~m} / \mathrm{s}$. Bora wind direction (roughly from NE) is, instead, completely consistent between the two runs in the northern Adriatic.

A description of the vertical structure of the bora flow can be obtained from the cross-sections of Fig. 5. These refer to 10:00 UTC 25 June and their position is along the line between points $Q$ and $T$ drawn in Fig. 4. This line lies approximately on the same direction of the low level wind above the sea. The represented fields are potential temperature (Fig. 5a), speed (Fig. 5b), zonal (Fig. 5c) and meridional (Fig. 5d) components of the wind as they are simulated by the high resolution run (run B). Shaded areas represent the step orography, Dinaric Alps are on the right, while the Italian coast is on the left of the figures; thus the bora flow must be followed from right to left.

The isentropes show an area of strong stability, near the mountain top level, and the descent of air towards the Adriatic Sea. Wind speed reaches a maximum $(16 \mathrm{~m} / \mathrm{s})$ at an height of about $1100 \mathrm{~m}$ just above the mountain top. During the descent of the flow another speed maximum is reached at an height of about $300 \mathrm{~m}$ above sea level.

The presence of a critical layer and the depth of the bora flow are seen from the cross-sections of the wind components (Figs. 5c and d). They show a flow approximately 

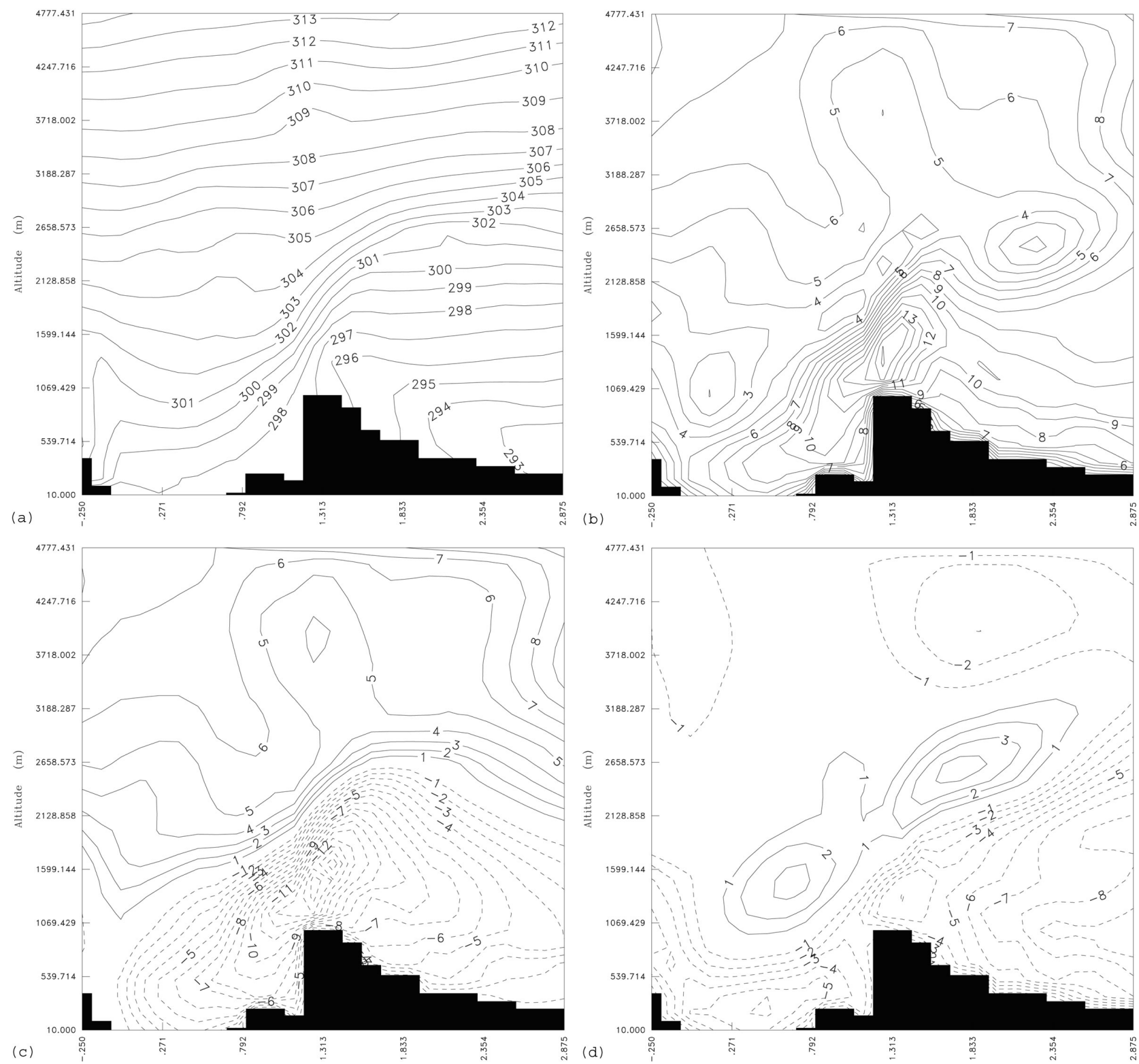

Fig. 6. Same as Fig. 5 but for the low resolution simulation (run A). Each division on the horizontal axis corresponds to about $80 \mathrm{~km}$.

from the northeast above which a different south-westerly flow blows. The bora thickness is about $2300 \mathrm{~m}$ upstream and about $800 \mathrm{~m}$ over the mountain top.

Same fields, along the same direction of Fig. 4, but obtained from the low resolution run (run A) are represented in Figs. 6a-d. Both resolution runs catch roughly the same characteristics of the bora wind, but with some remarkable differences.

The potential temperature vertical gradient above the mountain top is weaker in the case of the low resolution run and the low level air (below $1500 \mathrm{~m}$ ) in the area of Dinaric Alps is potentially warmer. Even if the maximum wind speed value over the mountain top is about the same for both runs, wind in the lee side is less intense if low resolution is adopted. This is in agreement with the $10 \mathrm{~m}$ wind behaviour.
Composite MCSST images show the thermal effect of the bora wind in the northern Adriatic (Fig. 7). The first one (Fig. 7a) refers to 24 June 2002, before the bora onset, while the other (Fig. 7b) refers to 26 June 2002. The images are nominally referred to 12:00 UTC. The map of 25 June is not available due to the presence of clouds during the whole day. A strong temperature decrease occurred and a mean differences of 5-6 K is seen in the areas interested by the two simulated wind streams. Buoy sea temperature measurements (not shown) in the Trieste Gulf indicate that such a cooling occurred in a short period of time (few hours) during the night between 24 and 25 June, immediately after the bora onset. This suggests an effect of marine thermal stratification demolition originated from water mixing. 

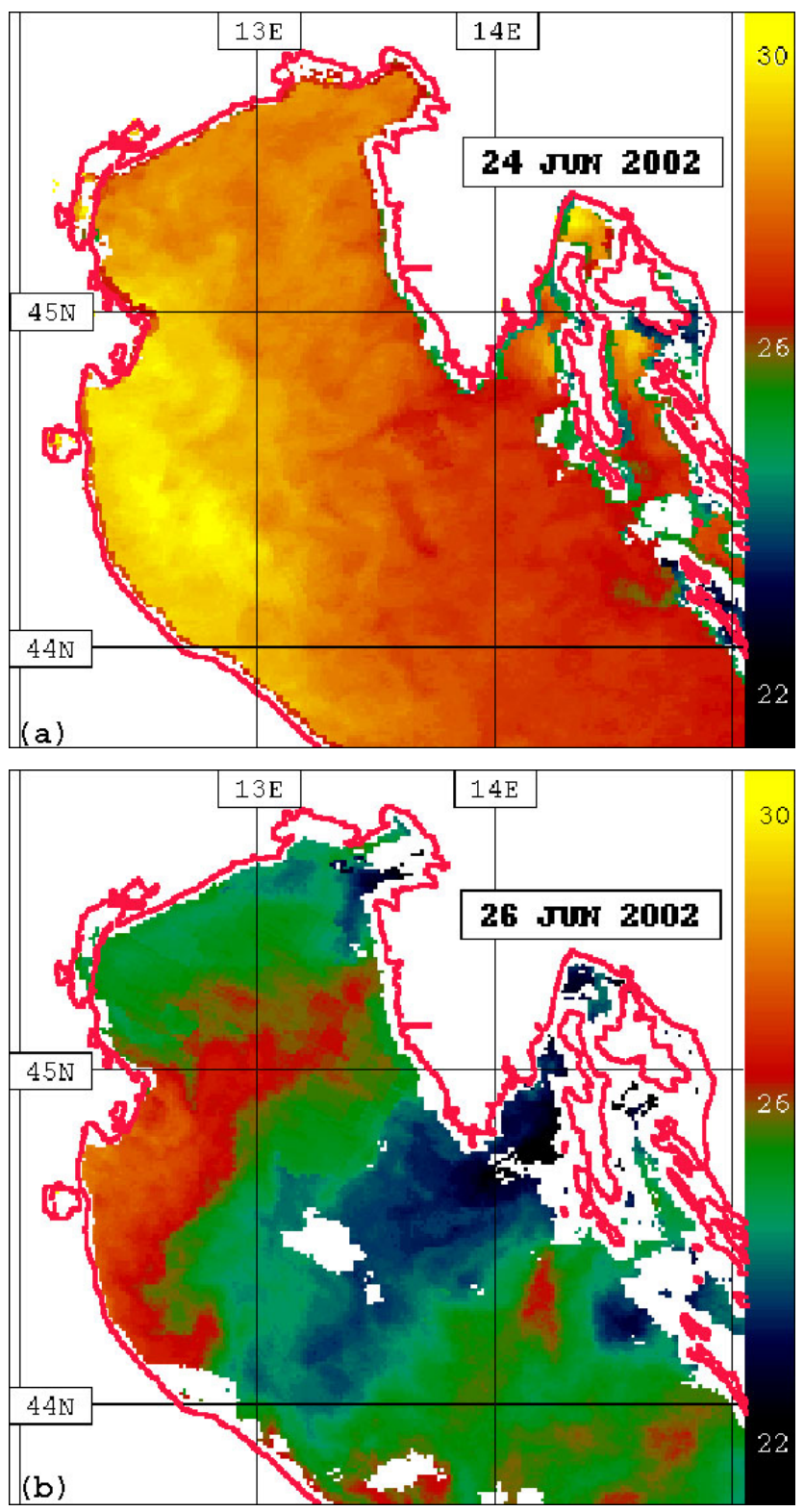

Fig. 7. Daily composite MCSST images of the northern Adriatic: (a) image of 24 June 2002; (b) image of 26 June 2002. Units are ${ }^{\circ} \mathrm{C}$.

The performed analysis indicates that both run B and $\mathrm{C}$ have similar characteristics; in spite of the differences between the initial sea surface temperatures used in the Eta model (Fig. 2b), the general behaviour of the simulated fields results alike. Some differences between them will be discussed in Sect. 6.

\subsection{Comparison with satellite data}

A comparison between cloud cover over the northern Adriatic region as observed by satellite and by model simulations was also performed. Figures $8 \mathrm{a}$ and $\mathrm{b}$ are AVHRR channel 2 images around 13:00 UTC on 25 and 26 June. The choice of this particular satellite pass among the about 8 of the day, comes from the knowledge it has the "best" view of the
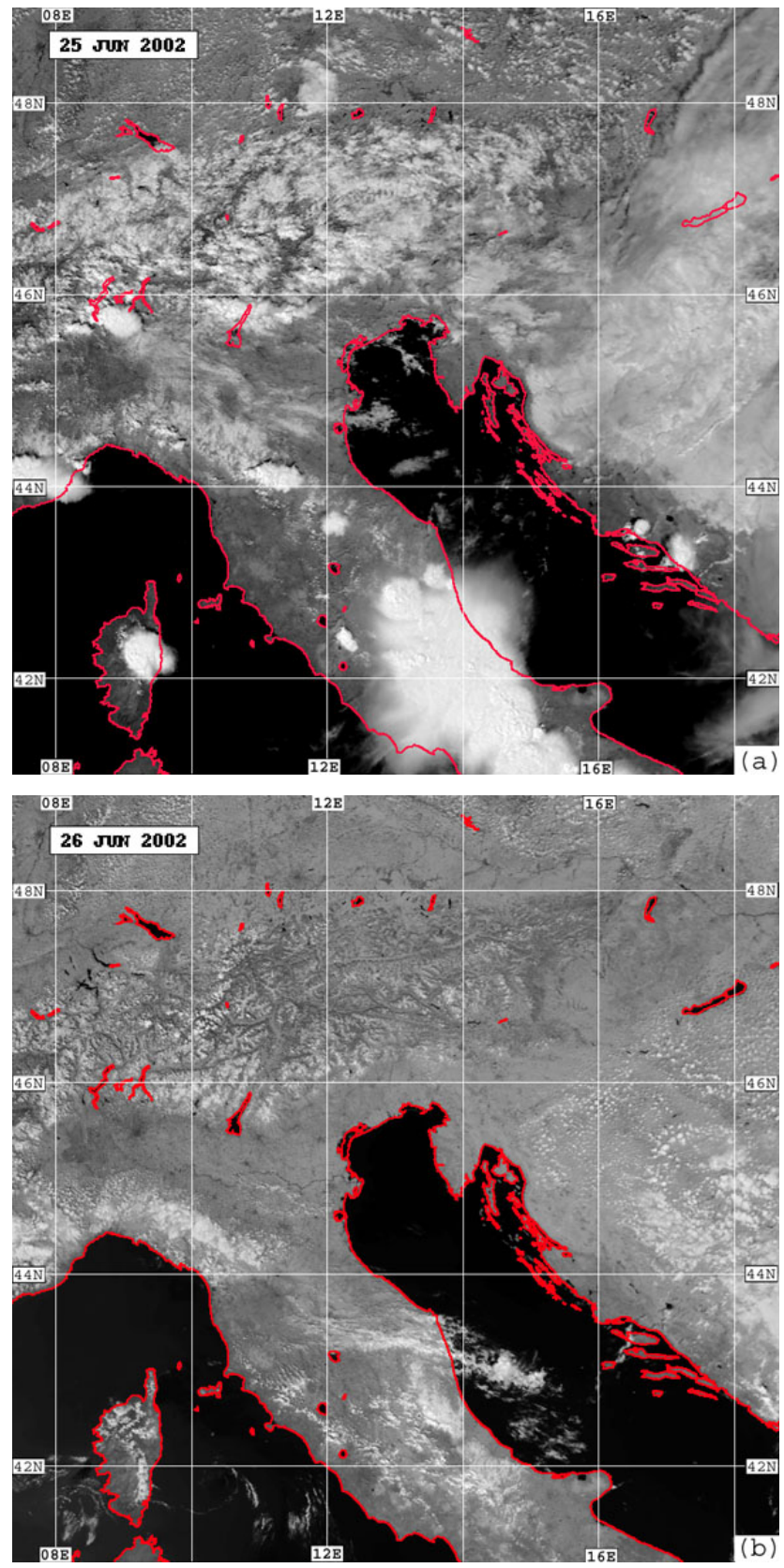

Fig. 8. AVHRR channel 2 view of cloud cover in the area of interest: (a) at about 13:00 UTC 25 June 2002; (b) at about 13:00 UTC 26 June 2002. In order to enhance the border between land and sea, a contrast stretching was applied to the images; this produced a masking of the thin clouds persisting over the northern Adriatic on 25 June, thin clouds that were otherwise detected by the MCSST algorithm.

northern Adriatic, i.e. with the lowest geometric distortion. The total cloud cover fractions as simulated by the coarse grid run at 13:00 UTC 25 June (Fig. 9a) and at 13:00 UTC 26 June (Fig. 9b) can then be compared with the corresponding satellite images. On 25 June a widespread cloud cover is present over the northern Adriatic, over central Italy and to east of the Dinaric Alps. Less cover is found over the Alps 

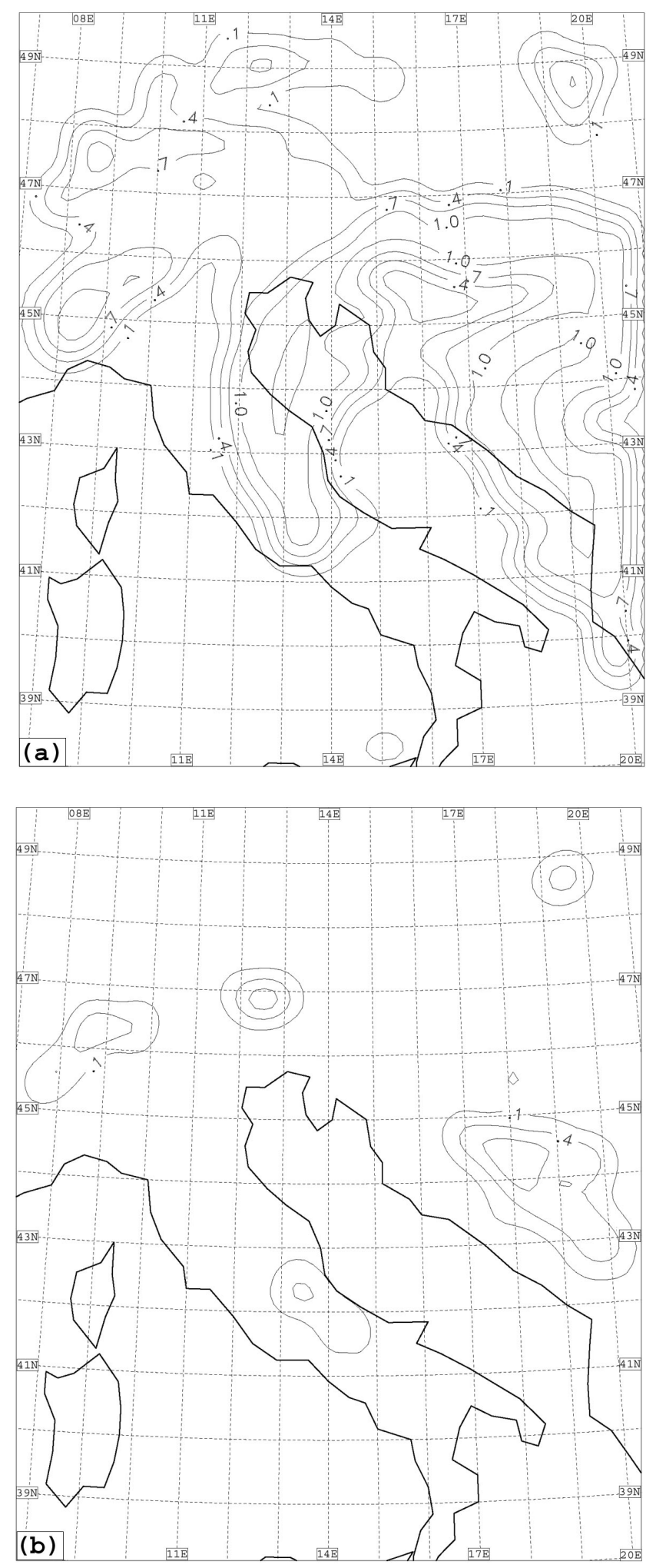

Fig. 9. Total cloud cover fraction calculated by the coarse grid run (run A): (a) at 13:00 UTC 25 June 2002; (b) at 13:00 UTC 26 June 2002. Contour line step is 0.3 . barrier. The clouds are progressively vanishing during the event and on 26 June no cloud remains in the interested area. Runs B and C confirm this behaviour and only small differences are present between them. Both runs show an area of total cloud cover only slightly larger than that simulated by the coarser grid. The cloud cover extends to the area around the point of coordinates $44^{\circ} \mathrm{N}, 11^{\circ} \mathrm{E}$, where the satellite image (Fig. 8a) reveals clouds. We can notice from the figures the good agreement between simulated and observed cloud cover fractions.

A further comparison was performed for low level winds. Figure 10 shows three maps of $10 \mathrm{~m}$ wind obtained with run B at the time of the QuikSCAT satellite passes during the bora event. The corresponding QuikSCAT measurements are presented. At 05:00 UTC 25 June, satellite data in the northern Adriatic are not displayed (because of high rain probability affecting the measurement), but south of the Istrian Peninsula they suggest the presence of a wind stream characterised by an intensity slightly higher than that calculated by the model. In fact, in the area included between $44^{\circ} \mathrm{N}$ and $45^{\circ} \mathrm{N}$ and between $13^{\circ} \mathrm{E}$ and $14^{\circ} \mathrm{E}$ the QuikSCAT wind speed ranges between $9 \mathrm{~m} / \mathrm{s}$ and $17 \mathrm{~m} / \mathrm{s}$, while the simulated maximum value is slightly lower than $12 \mathrm{~m} / \mathrm{s}$. More on the south, far away from the area interested by the bora, model and observational data substantially agree. At 18:00 UTC 25 June, the satellite and simulated data show that a decrease of the wind speed occurred. The model still presents two streams in the northern Adriatic; the stream south of the Istrian Peninsula has a lower intensity and spreads in a smaller area than that shown by satellite data. In the simulation, a third zone of high low level wind appears in the central Adriatic which is not detected by QuikSCAT. Simulated wind direction in this area is from $\mathrm{NW}$ and therefore, it can not be classified as bora, it is presumably associated with the quick pass of a low pressure in south-eastern Adriatic. At 04:00 UTC 26 June, the simulated two streams are linked by an area of uniform wind with a speed of about $9 \mathrm{~m} / \mathrm{s}$. QuickSCAT wind is stronger south of the Istrian Peninsula, and also in the central Adriatic, away from the bora region, where the observed wind has a main easterly component. The simulation intensifies a flow roughly parallel to the Italian coast, which is also present in the ECMWF analyses, used to initialize the Eta Model. The ECMWF $10 \mathrm{~m}$ wind is similar though weaker than that simulated. From the above comparison it results that the speed of the simulated bora wind is generally lower than that measured by satellite. The comparison of the position of the wind maxima is difficult because of the low resolution of satellite data, but the presence of two wind streams seems confirmed either by QuikSCAT observations and by MCSSTs (Fig. 7). In conclusion, numerous aspects of the simulations are found to be in agreement with the knowledge and the observations of the bora distinctive characteristics, thus supporting confidence in a general realism of the results. In particular, the finer grid run B presents a more realistic wind field over the Adriatic Sea in respect to the coarser grid run A, although the simulated bora speed compared with satellite data results 

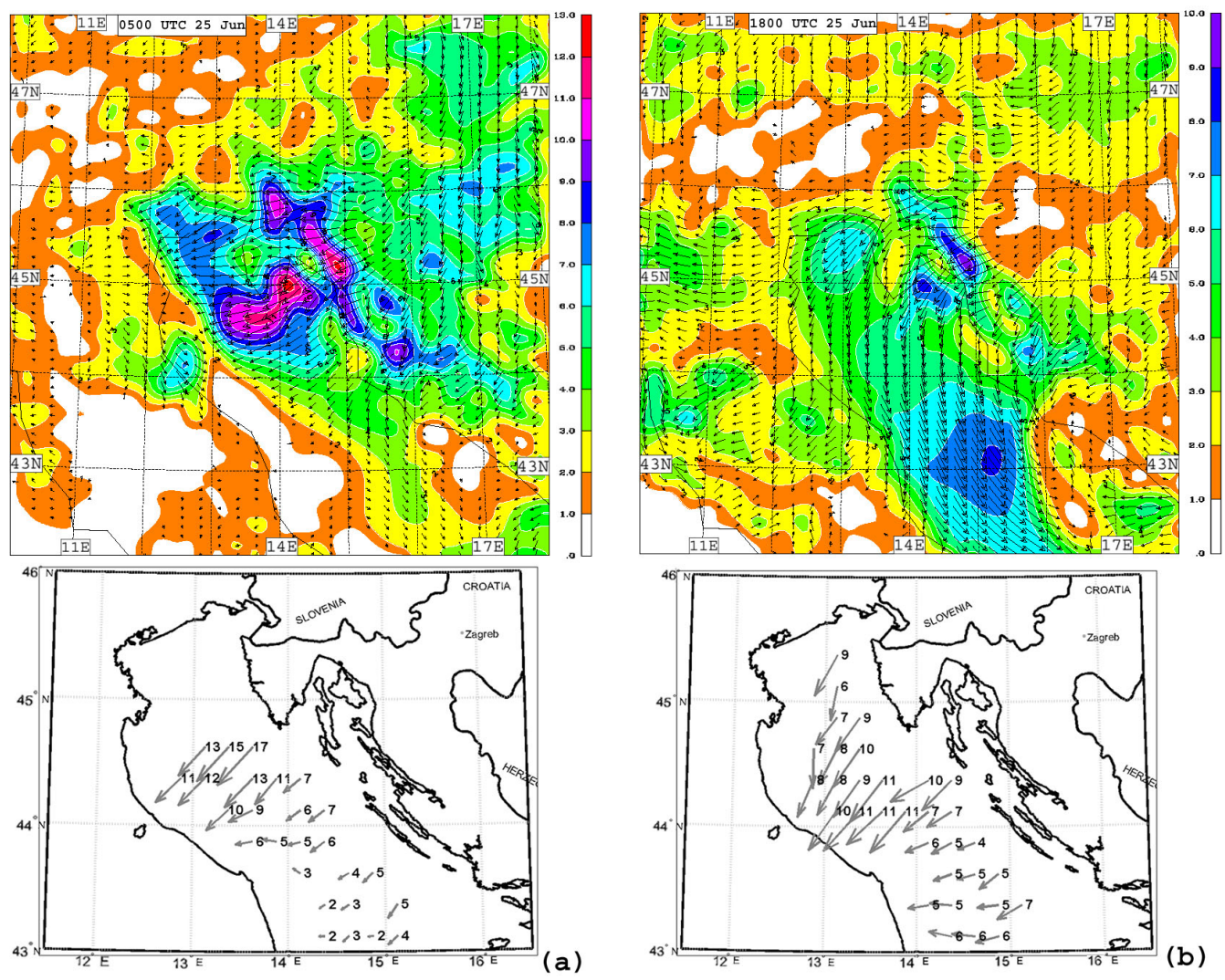

(b)
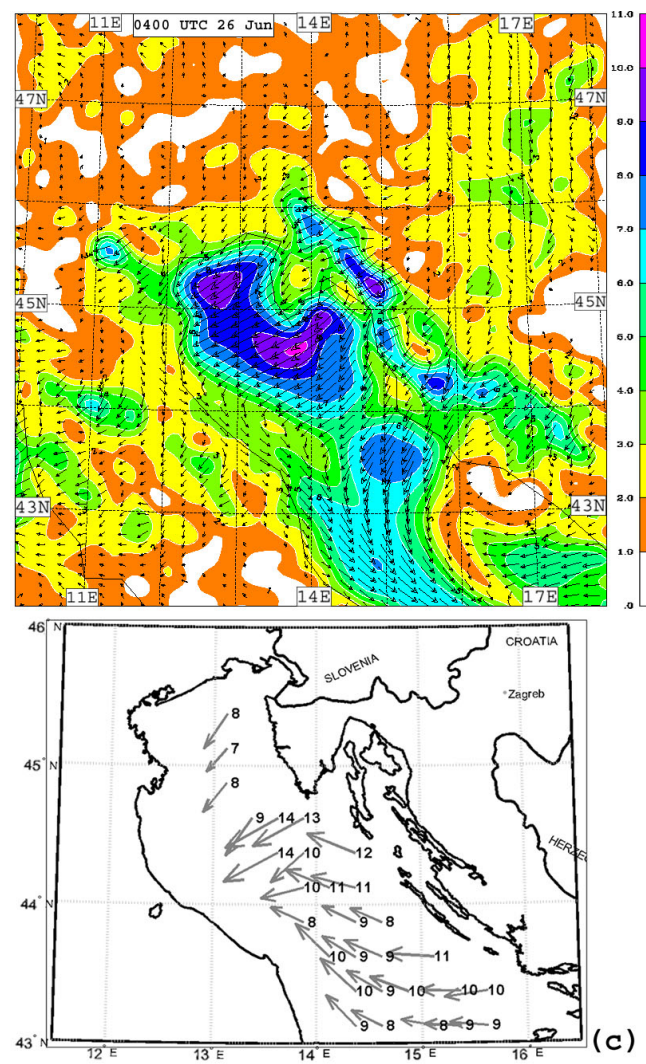

Fig. 10. Comparison of simulated $10 \mathrm{~m}$ wind (upper panel) with QuikSCAT wind measurements (lower panel): (a) at 05:00 UTC 25 June 2002; (b) at 18:00 UTC 25 June 2002; (c) at 04:00 UTC 26 June 2002. All winds are in m/s. Simulated wind vectors are drawn in a reduced number of points to obtain greater readability. No arrows in the upper panel are displayed if wind speed $<1 \mathrm{~m} / \mathrm{s}$. Every arrow in the lower panel is a measurement point. 


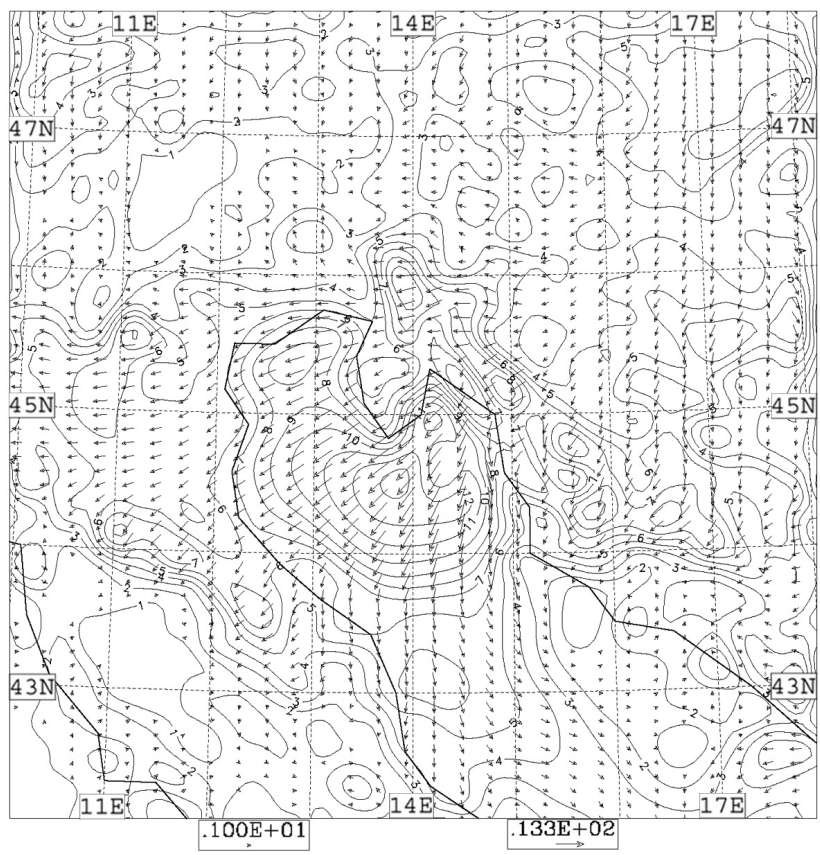

Fig. 11. Speed $(\mathrm{m} / \mathrm{s})$ and direction of the $10 \mathrm{~m}$ wind at 10:00 UTC 25 June 2002 simulated by the fine grid run (run C). Initial MCSST is used.

Contour line step is $1 \mathrm{~m} / \mathrm{s}$. Vectors are drawn in a reduced number of points to obtain greater readability. No arrows are displayed if wind speed $<1 \mathrm{~m} / \mathrm{s}$.

low. A similar comment is also suitable for run C. Further numerical simulations (not shown) of the same event were performed, integrating the Eta model, to study the dependence of the results from the model horizontal resolution (up to about $4 \mathrm{~km}$ ) and from the self-nested mode. The relative comparisons showed that the higher sensitivity of the wind field was obtained for the discussed resolution change. Apart from an expected enhancement of details and some differences, the $10 \mathrm{~m}$ wind over the sea did not show changes in its general pattern, significant for our purposes. For this reason, we have decided to run the SST sensitivity test at $8 \mathrm{~km}$ resolution and in not self-nested mode. In the Sect. 6 we shall refer only to this kind of simulation.

\section{The SST influence}

Observational studies (e.g. Jurčec, 1980/81), using data collected at Trieste (Italy) and in the Croatian area, suggest seasonal and diurnal variations in bora strength and occurrence. This wind occurs more frequently and with a greater intensity during winter and during night, when typically the temperature contrast between the land and the warm Adriatic Sea is more marked. On average, winter and night are periods characterised by sea warmer than the land, thus a higher sea temperature should favour the wind development.

The influence of the land-sea temperature contrast $\left(\Delta T_{L S}\right)$ on the bora wind was analysed by Enger and Grisogono (1998) with the help of idealised 2-D simulations; they found a strong correlation between the bora offshore propagation length and $\Delta T_{L S}$ : a relatively higher sea surface temperature in respect to the ground surface temperature meant a larger offshore propagation of the wind.

As previously described, run B and sensitivity run C only differ for the SST initialisation. Sea temperature in run B was initialised with ECSSTs, while in run C MCSSTs were used. Considering that the Eta model holds constant the SSTs in the course of a simulation, a change of this field can affect the results during the entire run. Figure $2 b$ shows MCSSTs are generally higher than ECSSTs. Differences are particularly evident along the western coast and in the area of the Trieste Gulf. On the whole, comparisons of the results of run B with the simulations of run $C$ reveal some differences over the northern and central Adriatic Sea. At the beginning of the bora episode, corresponding to the first hours of 25 June, the low level specific humidity results higher in run $\mathrm{C}$ with respect to run $\mathrm{B}$, in particular along the Italian coast. Besides, the higher MCSST affects the low level air instability condition over the sea. During the development of the event, the northern Adriatic Sea is characterized by an increasing difference between the near surface and $10 \mathrm{~m}$ potential temperature, resulting in a prevalent air instability. This difference is higher in run C; at 10:00 UTC 25 June, corresponding to the maximum wind speed, the average difference is about $2 \mathrm{~K}$ in run $\mathrm{B}$ and about $4 \mathrm{~K}$ in run $\mathrm{C}$. When using MCSSTs, crosssections of potential temperature (not shown), along the same line south of the Istrian Peninsula as in Fig. 5a, show, at times of high wind intensities, a lower downstream potential temperature as far as $400-500 \mathrm{~m}$ above the surface. Moreover, a stronger descent of air and slightly higher speed are present in wind speed cross-sections. At 10:00 UTC, the land surface temperature near the coast is about $21^{\circ} \mathrm{C}$ and is lower than the sea surface temperature. The $10 \mathrm{~m}$ wind is shown in Fig. 11 (to be compared with Fig. 4b). The maximum speed presents only a small difference of about $1 \mathrm{~m} / \mathrm{s}$ with respect to run $B$, reaching about $13 \mathrm{~m} / \mathrm{s}$. The air stream spreads over the sea and occupies a larger area than its counterpart (Fig. 4b) in run B. This result, obtained by a 3-D simulations of a real case of bora wind, appears in agreement with the study made by Enger and Grisogono with 2-D simulations. In the following, the differences in the low level wind calculated by two runs are analysed for the northern Adriatic (inside the Trieste Gulf), i.e. where ECSST and MCSST datasets mostly differ. Figures $12 \mathrm{a}$ and $\mathrm{b}$ show the $10 \mathrm{~m}$ wind calculated by both runs at 05:00 UTC 25 June. In run B (Fig. 12a) wind has its maximum intensity far from the coast and its direction is approximately constant between the points $P$ and $V$. In run C (Fig. 12b), instead, the region of higher wind speed is larger and the wind turns drastically in approaching point $V$ setting its direction from SE. In the two runs, the different surface temperatures and the associated thermal gradients generate modifications of the pressure field along the Italian coast which confine the offshore spreading of the north-easterly wind. In this case, the offshore propagation length results influenced in the early part of 25 June by the air circulation at the western and northern coasts. 


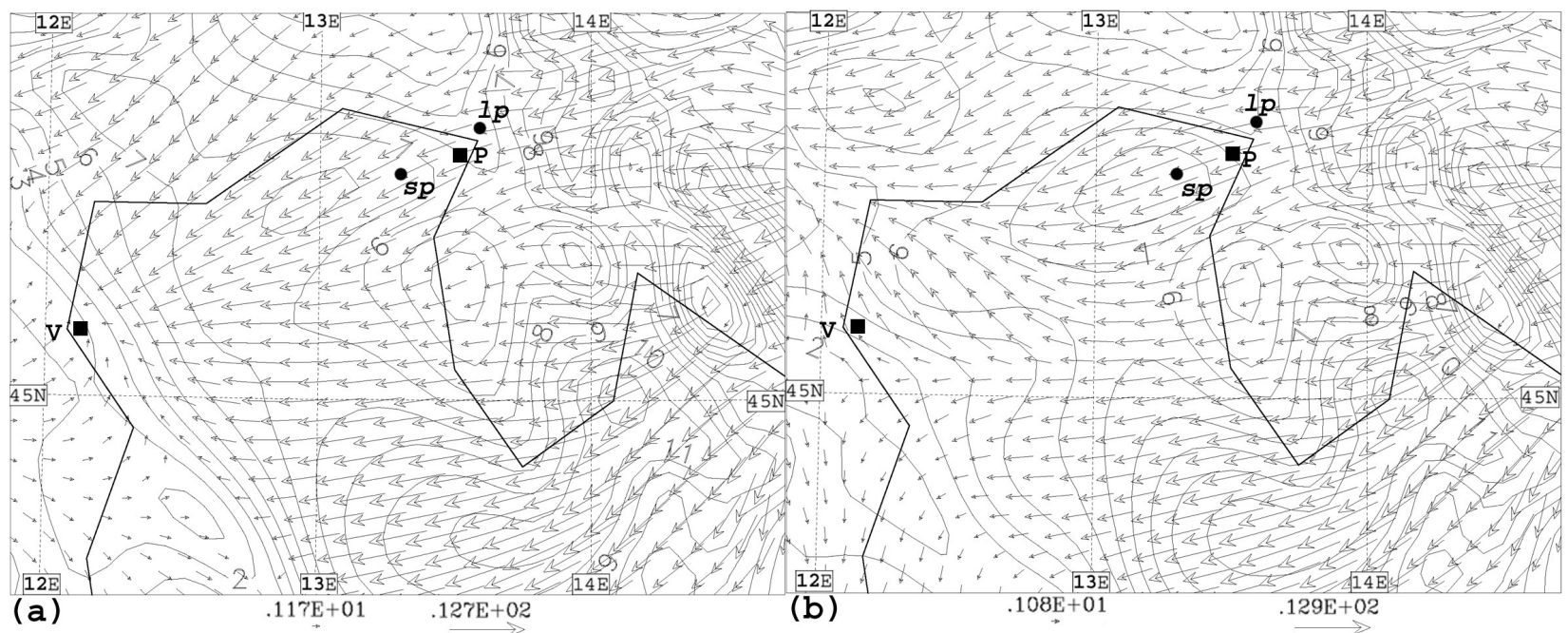

Fig. 12. Speed $(\mathrm{m} / \mathrm{s})$ and direction of the $10 \mathrm{~m}$ wind at 05:00 UTC 25 June 2002: (a) calculated by the fine grid simulation initialised with ECSSTs (run B); (b) calculated by the fine grid simulation initialised with MCSSTs (run C).

Contour line step is $1 \mathrm{~m} / \mathrm{s}$. The area shown is a portion of the integration domain; position of points quoted in the text is also shown.

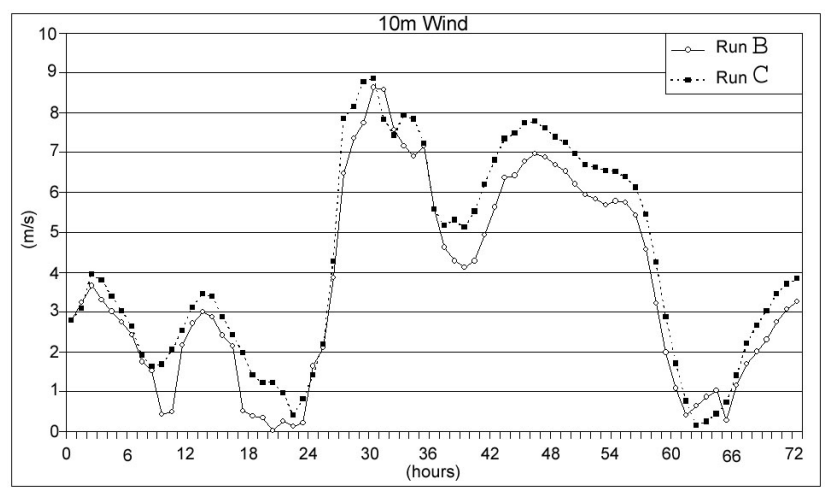

Fig. 13. Time series of the $10 \mathrm{~m}$ wind in a sea point located in the Trieste Gulf (denoted by $s p$ in Fig. 11) as calculated by the fine grid simulation initialised with ECSSTs (run B) and by the fine grid simulation initialised with MCSSTs (run C).

Later in the event, under clear-sky condition, low level wind direction is generally consistent between the two runs, while small (about $1 \mathrm{~m} / \mathrm{s}$ ) wind speed differences result. The time series of the simulated $10 \mathrm{~m}$ wind in a point located inside the gulf $\left(13.29^{\circ} \mathrm{E}, 45.60^{\circ} \mathrm{N}\right.$, denoted by $s p$ in Fig. 12) is shown in Fig. 13. Both runs show a wind speed maximum after about 29-30 h of simulation (at about 05:00 UTC 25 June), the intensity then decreases reaching a minimum after about $40 \mathrm{~h}$ (at 16:00 UTC 25 June) before rising again. The end of the event occurs after about $60 \mathrm{~h}$ (at 12:00 UTC 26 June) after the simulations onset. Figure 14 shows the temporal evolution of the surface temperature difference $\left(\Delta T_{L S}\right)$ between a land point $\left(13.64^{\circ} \mathrm{E}, 45.75^{\circ} \mathrm{N}\right.$, denoted by $l p$ in Fig. 12) and the previous sea point as calculated by run B and run C. Land point was chosen near Trieste approximately in the $10 \mathrm{~m}$ wind direction at the sea point. Nega-

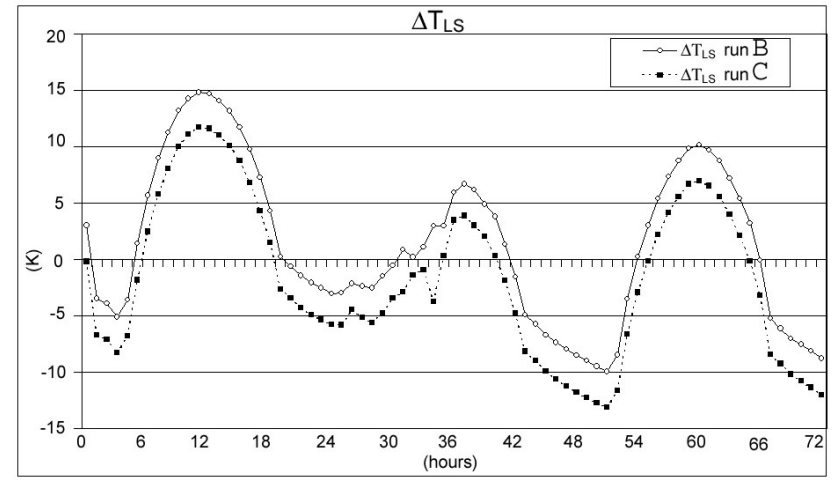

Fig. 14. Time series of the temperature difference $\left(\Delta T_{L S}\right)$ between a land point near Trieste (denoted by $l p$ in Fig. 11) and a sea point in the Trieste Gulf (denoted by $s p$ in Fig. 11).

tive values of $\Delta T_{L S}$ mean sea is warmer than land. Because the SSTs are fixed to the initial values during simulations, $\Delta T_{L S}$ modulation is only caused by land temperature variations. Both runs show a correlation between wind speed and $\Delta T_{L S}$ : wind maxima occur roughly in coincidence with minima of the temperature contrast. Besides, the higher sea temperature introduced in run $\mathrm{C}$ lowers the $\Delta T_{L S}$ minima and this produces a slightly stronger low level wind in the second part of the event.

Overall, the substitution of ECSSTs with the satellite data did not produce large variations on the simulation results; these, however, suggest a sensitivity of the wind speed and direction, simulated with $8 \mathrm{~km}$ horizontal resolution, to the SST field change. 


\section{Conclusion}

Bora is a severe northeasterly low level wind, coming down from the Dinaric Alps along the eastern Adriatic coast. The air flow can reach high speed and spread over great distances towards the Italian coast.

A real bora event, occurred in the period 24-27 June 2002, is simulated by the Eta limited area model. Three hydrostatic simulations, differing in the horizontal resolution and in the initial SST values, are presented. Sea surface temperatures, interpolated to the Eta model grid, remain constant to the initial values throughout the simulations. Two reference runs, initialised with ECMWF sea skin temperatures (ECSSTs), are performed at the horizontal resolution of $20 \mathrm{~km}$ and $8 \mathrm{~km}$, respectively. A further simulation (at $8 \mathrm{~km}$ horizontal resolution) is initialised with MCSSTs obtained from the satellite pass closest to the model integration starting time. ECMWF analysis provides the other initialisation and boundary condition data. All simulations are carried out with 50 layers in the vertical. Sea wind data, provided by QuikSCAT satellite and downloaded from NASA/PODAAC at JPL, are used for comparison. The use of satellite sea surface temperatures is made difficult in wintertime bora cases as these are often characterised by overcast sky. In this paper the difficulties are alleviated by the choice of a summertime event.

Simulations show that a realistic representation of the low level wind is achieved using the higher horizontal resolution. Two main air streams are simulated: one, stronger and wider, is located south of Istrian Peninsula, the other is in the Trieste Gulf. The comparison with observational data reveals that the simulated low level wind speed is generally lower than that measured by satellite, but we have to remember that the numerical simulations typically represent quantities averaged over the area of a mesh.

MCSSTs, used to initialize the Eta Model at $8 \mathrm{~km}$ horizontal resolution, are some degrees higher than ECSSTs along the coastal areas of the northern Adriatic Sea and in the area of the Trieste Gulf. The impact of the difference in the initial SST is evaluated. The higher MCSSTs affect the low level specific humidity and the instability condition over the sea. The low level wind speed maxima are weakly influenced by the SST change but the area interested by the southern flow tends to increase when relatively higher sea surface temperatures are used. A larger area with relatively high wind speed suggests an agreement with 2-D simulations carried on by Enger and Grisogono (1998). The warmer SSTs and the different thermal gradients across the Italian coasts slightly modify the low level circulation in the Trieste Gulf, confining the offshore propagation of the north-easterly wind. Near the Po river estuary, the wind is mainly south-easterly during the first part of the event. Temporal evolution of the $10 \mathrm{~m}$ wind speed, simulated near the coast in the Trieste Gulf, is affected by the thermal contrast between land and sea and shows a sensitivity in the last part of the event to the SST changes introduced into the simulations.

MCSST images put in evidence the strong interaction between the bora wind and the sea skin temperatures, the lat- ter being significantly reduced after the event. The available MCSST images (limited by the presence of a widespread clouds cover over the Adriatic Sea on 25 June 2002) show that at least in $48 \mathrm{~h}$ the areas interested by the bora flow experienced a sea skin temperature reduction up to $7-8 \mathrm{~K}$ in some point. A bora event occurred in spring 1999 is described by Stravisi (www.dst.univ.trieste.it/OM/bora/BORA.html): by conventional sea temperature measurements in the Trieste Gulf, Stravisi shows that the mixing, due to the wind, quickly decreases of some degrees the water surface temperature.

Usually weather forecast models keep SST fixed at the integration starting time; this is done on the assumption that sea temperature is a slowly varying variable. Satellite data show that such an assumption could not always hold for small and shallow basin like the Adriatic Sea during bora events. A question to answer is if the timescales in these cases allow to produce significant two-way interaction response between the air and SST and at what extent the bora forecast could be improved by introducing a varying sea surface temperature in the model integration. In the studied episode, the simulations reveal sensitivity to the initial SST difference, although their influence on $10 \mathrm{~m}$ wind is weak. The overall air-sea interaction system includes the SST evolution. In order to evaluate this aspect, one should strictly couple meteorological and oceanographic models.

Acknowledgements. This study was carried out with the contribution of a research fellowship by the "Modena and Reggio Emilia University" and founded by the "Italian Space Agency" (ASI). Aeronautica Militare (Italy) has authorised the admittance to the ECMWF archive. The authors thank the referees for their assistance during the evaluation process. This paper was presented at the EGS-AGU-EUG Joint Assembly, Nice, France, 2003 in the session "Diagnosis, modelling and forecasting of natural hazards produced by extreme weather and climate change".

Edited by: U. Ulbrich

Reviewed by: two referees

\section{References}

Arakawa, A. and Lamb, V. R.: Computational design of the basic dynamical processes of the UCLA general circulation model, Methods Comput. Phys., 17, 173-265, 1977.

Beg Paklar, G., Isakov, V., Koraćin, D., Kourafalou, V., and Orlić, M.: A case study of bora-driven flow and density changes on the Adriatic Shelf (January 1987), Continental Shelf Research, 21, 1751-1783, 2001.

Camuffo, D.: Acidic precipitation research in Italy, Acidic precipitation monograph, Advances in Environ. Sci., 5, 229-265, 1990.

Chen, F., Mitchell, K., Schaake, J., Xue, Y., Pan, H., Kore, V., Duan, Q. Y., Ek, M., and Betts, A.: Modelling of the land surface evaporation by four schemes and comparison with FIFE observations, J. Geophys. Res, 101(D3), 7251-7268, 1996.

Clark, T. L. and Peltier, W. R.: On the evolution and stability of finite-amplitude mountain waves, J. Atmos. Sci., 34, 1715-1730, 1977. 
Clark, T. L. and Peltier, W. R.: Critical level reflection and the resonant growth of nonlinear mountain waves, J. Atmos. Sci., 41, 3122-3134, 1984.

Doyle, J. D.: Coupled Atmosphere-Ocean Wave Simulations under High Wind Conditions, Mon. Wea. Rev., 130, 3087-3099, 2002.

Durran, D. R.: Mountain waves and downslope winds, Meteorological monographs, Atmospheric processes over complex terrain, 23, 59-81, 1990.

Eliassen, A. and Palm, E.: On the transfer of energy in stationary mountain waves, Geofys. Publ., 22, 1-23, 1961.

Enger, L. and Grisogono, B.: The response of bora-type flow to sea surface temperature, Q.J.R. Meteorol. Soc., 124, 1227-1244, 1998.

Georgelin, M., Richard, E., Petitdidier, M., and Druilhet, A.: Impact of subgrig-scale orography parameterisation on the simulation of orography flows, Mon. Wea. Rev., 122, 1509-1522, 1994.

Ivančan-Picek, B. and Tutiš, V.: A case study of a severe Adriatic bora on 28 December 1992, Tellus, 48A, 357-367,1996.

Janjić, Z. I.: The step mountain coordinate model: further developments of the convection, viscous sublayer and turbulence closure scheme, Mon. Wea. Rev., 122, 927-945, 1994

Janjić, Z. I.: The Mellor-Yamada level 2.5 turbulence closure scheme in the NCEP Eta Model, Research Activities in Atmospheric and Oceanic Modellig, WMO, Geneva, CAS/WGNE, 4.14-4.15, 1996.

Jurčec, V.: On mesoscale characteristics of bora conditions in Yugoslavia, Pure and Applied Gephys., 119, 641-657, 1980/1981.

Klemp, J. B. and Durran, D. R.: Numerical modelling of bora winds, Meteorol, Atmos. Phys., 36, 215-227, 1987.

Klemp, J. B. and Lilly, D. K.: The dynamics of wave induced downslope winds, J. Atmos. Sci., 32, 320-339, 1975.

Lazić, L., and Tošić, I.: A real data simulation of the Adriatic bora and the impact of mountain height on bora trajectories, Meteorol. Atmos. Phys., 66, 143-155, 1998.

Lobocki, L.: A procedure for the derivation of surface-layer bulk relationship from simplified second order closure models, J. Appl. Meteor., 32, 126-138, 1993.

Long, R. R.: Some aspects of the flow of stratified fluids, I. A theoretical investigation, Tellus, 5, 42-58, 1953.

Long, R. R.: Some aspects of the flow of stratified fluids, II. Experiments with a two-fluid system, Tellus, 6, 97-115, 1954.

Long, R. R.: Some aspects of the flow of stratified fluids, III. Continuous density gradients, Tellus, 7, 341-357, 1955.
McClain, E. P., Pichel, W. G., and Walton, C. C.: Comparative performance of AVHRR-based Multichannel Sea Surface Temperature, J. Geophys. Res., 90, C6, 11 587-11 601, 1985.

Mesinger, F.: A blocking technique for the representation of mountains in atmospheric models, Riv. Met. Aeronautica, 44, 195 202, 1984.

Mesinger, F. and Black, T. L.: On the impact of forecast accuracy of the step mountain (eta) vs. Sigma coordinate, Meteor. Atmos. Phys., 50, 47-60, 1992.

Mesinger, F. and Collins, W. G.: Review of the representation of mountains in numerical weather prediction models. Observation, theory and modelling of orographic effects, Seminar at ECMWF, Reading, UK, 2, 1-28, 1986.

Mesinger, F., Janjić, Z. I., Nicković, S., Gavrilov, D., and Deaven, D. G.: The step mountain coordinate: model description and performance for cases of alpine lee cyclogenesis and for a case of an Appalachian redevelopment, Mon. Wea. Rev., 116, 1493-1518, 1988.

Morelli, S. and Berni, N.: On a bora event simulated by the Eta model, Meteorol. Atmos. Phys., 84, 11-22, 2003.

Orlić, M., Kuzmić, M., and Pasarić, Z.: Response of the Adriatic Sea to the bora and sirocco forcing, Cont. Shelf Res., 14, 91116, 1994

Paulson, C. A.: The mathematical representation of wind speed and temperature profiles in the unstable atmospheric surface layer, J. Appl. Meteor., 9, 857-861, 1970.

Rachev, N. and Purini, R.: The Adriatic response to the bora forcing: A numerical study, Nuovo Cimento C, 24, 303-311, 2001.

Robinson, I. S., Wells, N. C., and Charnock, H.: The sea surface thermal boundary layer and its relevance to the measurement of sea surface temperature by airborne and spaceborne radiometers, Review Article, Int. J. Remote Sensing, 5.1, 19-45, 1984.

Smith, R. B.: On severe downslope winds, J. Atmos. Sci., 42, $2597-$ 2603, 1985.

Smith, R. B.: Aerial observation of the Yugoslavian bora, J. Atmos. Sci., 44, 269-297, 1987.

Smith, R. B. and Sun, J.: Generalized hydraulic solutions pertaining to severe downslope winds, J. Atmos. Sci., 44, 2934-2939, 1987.

TeraScan User Manual, SeaSpace Corp., Poway, California, 2002.

Yoshino, M. M.: Local Wind bora, Univ. of Tokyo Press, 289, 1976.

Zhao, Q., Black, T. L., and Baldwin, M. E.: Implementation of the cloud prediction scheme in the Eta model at NCEP, Wea. Forecasting, 12, 697-712, 1997. 